\title{
OPTIMIZATION MODEL FOR SCHOOL TRANSPORTATION DESIGN BASED ON ECONOMIC AND SOCIAL EFFICIENCY.
}

\author{
Sara Ezquerro Eguizábal \\ Researcher, University of Cantabria, Spain \\ José Luis Moura Berodia \\ Associate Professor, University of Cantabria, Spain \\ Ángel Ibeas Portilla \\ Associate Professor, University of Cantabria, Spain \\ Juan Benavente Ponce \\ Researcher, University of Cantabria, Spain
}

\begin{abstract}
The purpose of this paper is to design a model that allows to suggest new planning proposals on school transport, so that greater efficiency operational will be achieved. It is a multiobjective optimization problem including the minimization of the cost of busing and minimizes the total travel time of all students. The foundation of the model is the planning routes made by bus due to changes in the starting time in schools, so the buses are able to perform more than one route.

The methodology is based on the School Bus Routing Problem, so that routes from different schools within a given time window are connected, and within the restrictions of the problem, the system costs are minimized. The proposed model is programmed to be applied in any generic case.

This is a multi-objective problem, in which there will be several possible solutions, depending on the weight to be assigned to each of the variables involved, economic point of view versus social point of view. Therefore, the proposed model is helpful for policy planning school transportation, supporting the decision making under conditions of economic and social efficiency.

The model has been applied in some schools located in an area of Cantabria (Spain), resulting in 71 possible optimal options that minimize the cost of school transport between $2,7 \%$ and $35,1 \%$ regarding to the current routes of school transport, with different school start time and minimum travel time for students.
\end{abstract}

\section{INTRODUCTION}

School transport in Spain is a Special Regulated Public Transport Service financed by the autonomous communities through public tenders per school year and represents a heavy 
financial burden for them. This is partially due to the difficulties companies have in using the vehicles for other purposes during the rest of the day, and the existence of historically defined routes which have never been subjected to a process of scrutiny to optimise them as well as the rigid school timetables.

The main goal of this study is to design an optimisation model which will allow proposals for route planning to be defined in such a way that they will maximise efficiency from operational, economic and social points of view. Opening and closing times of schools will be modified by establishing time windows which will allow the buses to cover one school route and then be able to cover another school route (see Figure 1).

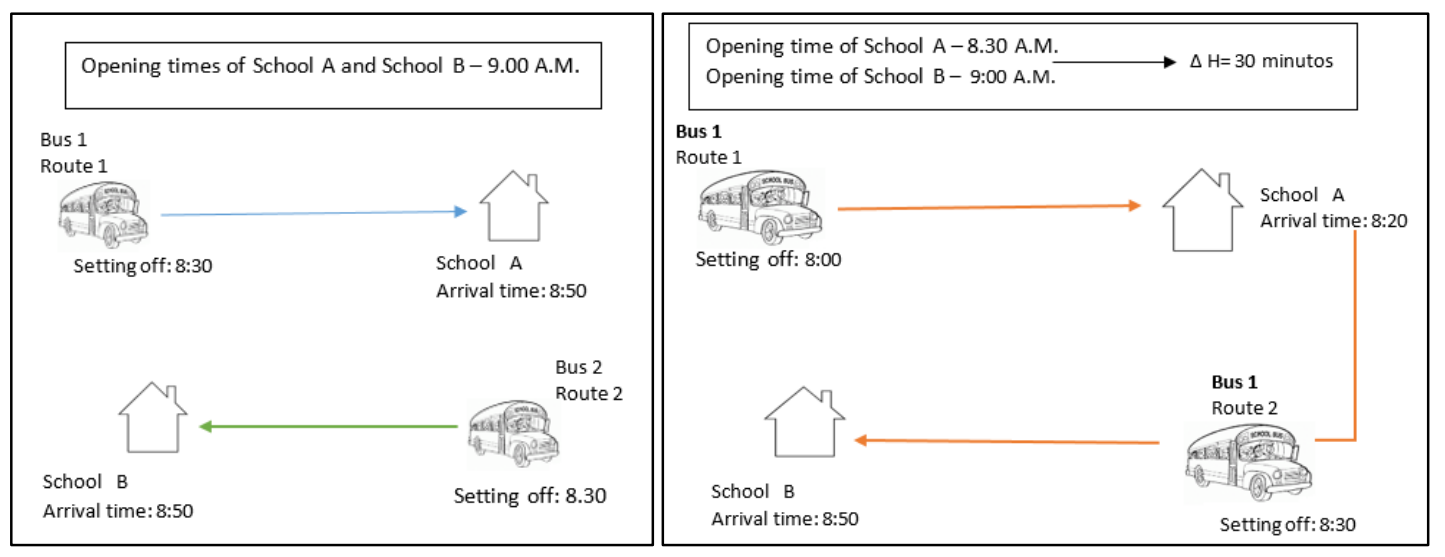

\section{Figure 1. The main idea (before-after)}

The aim of the research is to simultaneously optimise the group of school routes and the connections between them. These are created from the differences between the school opening times in such a way that the routing problem is dependent on the problem of combining the timetables and vice versa.

The analysis and research are aimed at finding a balance between profitability and quality of service, making it a problem of multiple objectives: economic (cost optimisation, regional government) and social objectives (optimisation of journey time, users).

The initial hypotheses were that the bus capacities were homogenous and they should arrive at the school between 2 and 10 minutes before the schools open so that the students arrive in time at their classrooms but do not have to wait too long. The locations of the stops, the number of students at each stop and the destination school will also be basic input data.

\section{STATE OF THE ART}

Many works are available which describe research aimed at optimising school transport. Authors have proposed the possibility of changing school opening and closing times while considering the school transport routes to be fixed (Kim et al, 2011). However, few authors 
have proposed making changes to school timetables to minimise service costs at the same time as addressing the problem of each individual school route taking into account the journey time of the students.

In an initial approach, the problem of school transport can be addressed as a SBRP (School Bus Routing Problem) (Schittekat et al., 2013) which is a variation of a VRP (Vehicle Routing Problem) where there is more than one objective to minimise.

On the other hand, Desrosiers et al. (1980), added a maximum time constraint on each student's journey and/or time window, for their arrival at school. Furthermore, $\mathrm{Li}$ and $\mathrm{Fu}$ (2002) presented an approach with multiple objectives where the number of buses, the bus journey time and the students' journey times are minimised. Fugenschuh (2009) considered the problem of programming the school bus by allowing the school opening times to be adapted to the transfer of the students during the journey based on VRPTW (Vehicle Routing Problem Time Window), but considered the routes to be basic input data.

As described below, our problem differs from those mentioned above in several ways. The routing problem is solved at the same time as the vehicle planning problem in order to minimise journey times for the students and minimise the number of buses being used within different time windows. This will allow future decision makers to give weight to these two economic and social criteria.

\section{METHODOLOGY}

The multiple objective optimisation model is a support tool for future decision makers. There will no single solution, but rather various solutions making up a group of solutions which are in equilibrium between the economic and social factors. The objective function of the model is shown in expression 1 which will be decisive in planning school transport giving weight to the variables $(\alpha, \beta)$.

$$
\operatorname{Min}(\alpha \cdot \text { operating costs }+\beta \cdot \text { user costs })
$$

The schematic shown in figure 2 was used in the development of the optimisation model and developed in the following iterative way:

- First phase, the routing problem for each school is solved. Variables are the number of routes serving each school and the maximum journey time allowed on them.

- Second phase, an optimisation model is used to solve the route combination problem; various routes are created for the same bus within the necessary time window, thereby providing multiple alternatives for the planning problem. 
- Third phase, a pre-analysis is performed on all the alternatives obtained to differentiate which of them could minimise the objective function (for different values of $\alpha$ and $\beta$ ), and which are, therefore, solutions to the model.

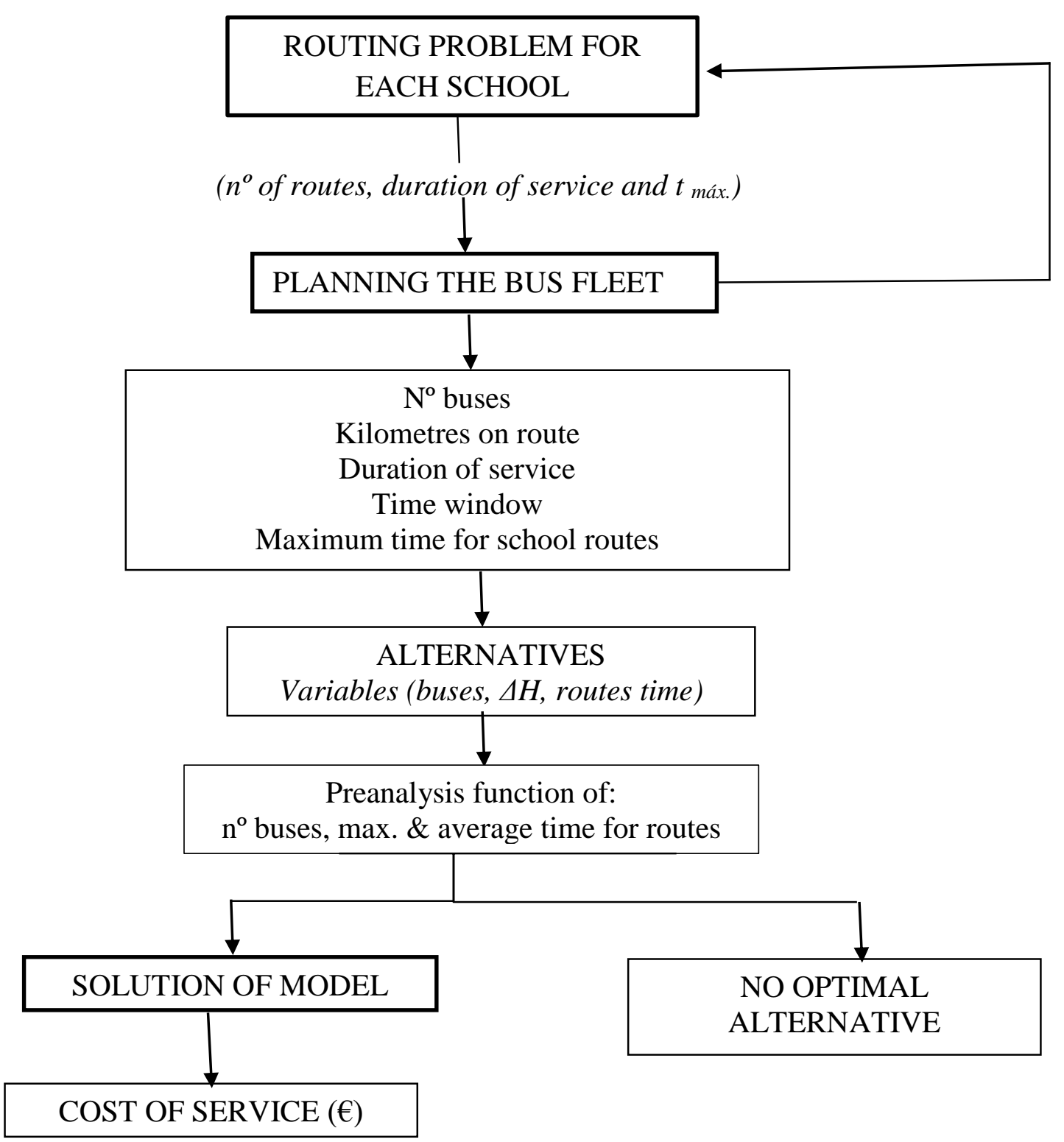

\section{Figura 2. Methodology}

\subsection{Routing problems for each school}

The routing problem for each school was solved using SBRP. The SBRP problem can be understood as the intersection of two well-known optimisation problems. The first, the problem of $m$ travelling agents ( $m$-TSP) is a generalisation of the TSP (Travelling Salesman Problem) and is aimed at creating exactly m routes, one for each vehicle, so that each stop is served once by one of the vehicles. The second problem is that of packaging, consisting 
of picking up a group of students where their total number is not greater than the capacity of the bus.

In the solution of SBRP exactly $\mathrm{m}$ routes need to be created, this number of routes is variable and will be defined by:

$$
\begin{gathered}
n^{\text {o }} \text { routes } \min ^{A} \leq n^{\mathrm{o}} \text { routes }^{A} \leq n^{\mathrm{o}} \text { routes } \max ^{A} \\
\frac{N^{\mathrm{o}} \text { est }^{A}}{C} \leq n^{\mathrm{o}} \text { routes }^{A} \leq \frac{N^{\mathrm{o}} \text { est }^{A}}{0.5 \cdot C}
\end{gathered}
$$

Where:

- $\quad \mathrm{N}^{\mathrm{o}}$ est.: the number of pupils going to school A.

- C: capacity of the buses.

A further variable has also been added to this problem, the maximum permitted route time. This represents a constraint on the routing problem which limits the duration of the routes and will change in 15 minute intervals, up to the maximum of 60 minutes fixed by the rule.

The routing problem for each school will not have a unique solution, there will be various solutions, representing the sum of the combinations of these variables, number of routes and their maximum travelling time ( $\mathrm{n}^{\mathrm{o}}$ routes, $\mathrm{t}_{\max }$ ) where a solution is possible. This knowledge provides the routes and their duration.

\subsection{Planning the bus fleet}

Once the routing problem have been solved for each school, the following step is to plan the size of the bus fleet so that a bus is available to cover routes serving one or more schools within a time window, which cannot be greater than 60 minutes. In other words, the aim is to minimise the number of buses required, which is the same as minimising the economic costs, taking into account journey route times and time window of all possible combinations The objective function of this vehicle planning problem (ec.4) addresses the need to find the minimum combination required to serve the set of schools (Z). Each combination is obtained from the Cartesian product of schools and sets (ec. 5 and 6).

Equation 7 shows that the number of buses required is the difference between the number of routes of each individual school and the number of connections between them.

$$
\begin{gathered}
\operatorname{Min}(\text { Comb }) \\
\operatorname{Comb}=A \times C^{A}=\left\{A, C^{A}: A \in Z \text { y C }{ }^{A} \in \operatorname{Set}^{A}\right\}
\end{gathered}
$$




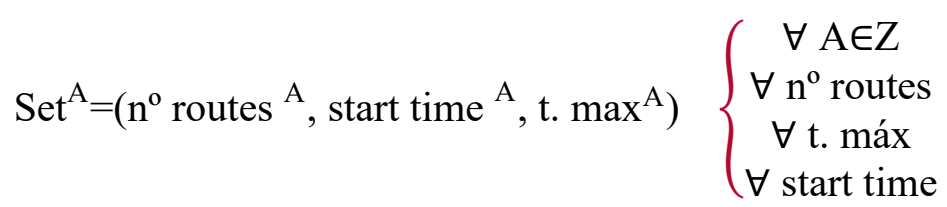

$$
\mathrm{N}^{\mathrm{o}} \text { buses }_{\text {Comb }}=\sum_{\mathrm{A} \in \mathrm{Z}} \mathrm{N}^{\mathrm{o}} \text { routes }^{\mathrm{A}}-\sum_{\mathrm{A} \in \mathrm{Z}} \mathrm{N}^{\mathrm{o}} \text { Connec }^{\mathrm{A}} \quad \forall \text { Comb }
$$

S.a.:

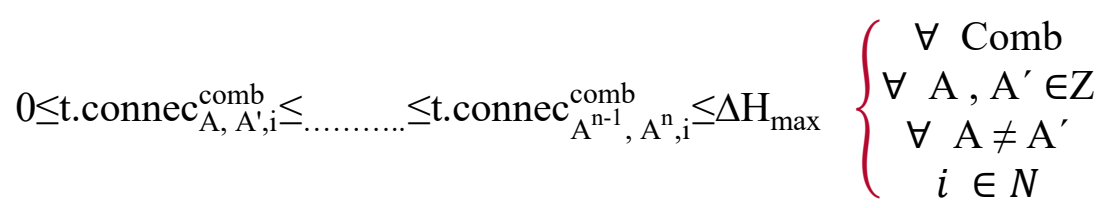

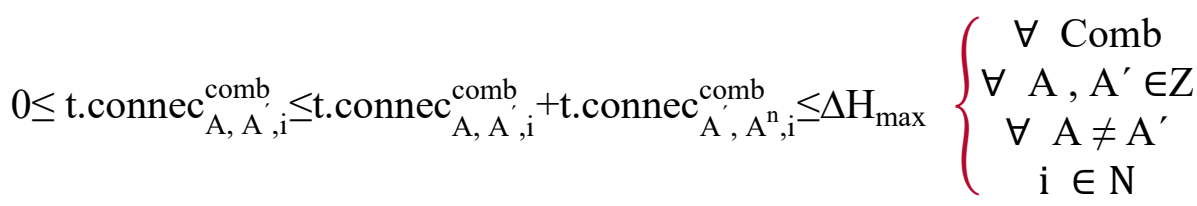

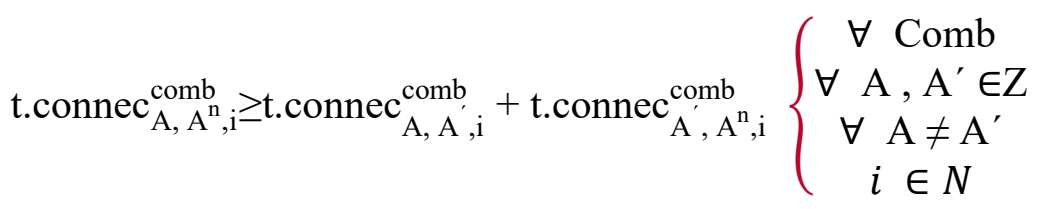

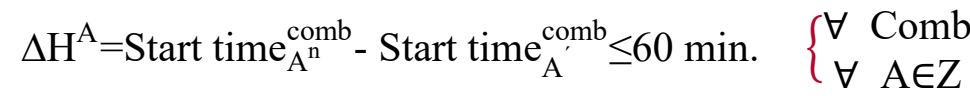

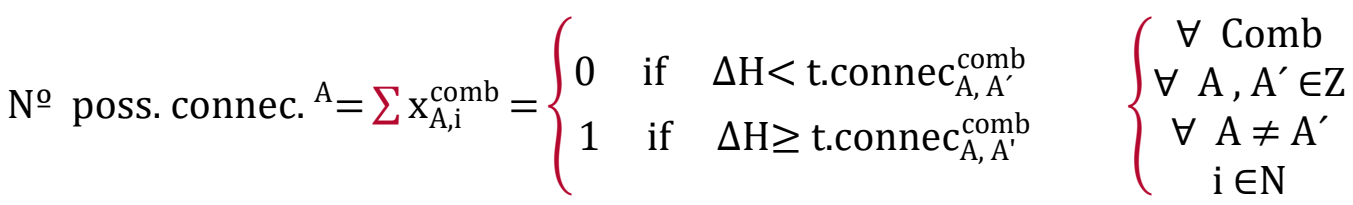

$$
\begin{aligned}
& \text { t.connec }_{\mathrm{A}, \mathrm{A}^{\prime}, \mathrm{i}}^{\mathrm{comb}}=\left\{\begin{array} { l l l } 
{ 0 } & { \text { if } } & { \Delta \mathrm { H } < \mathrm { t } \cdot \operatorname { c o n n e c } _ { \mathrm { A } , \mathrm { A } ^ { \prime } } ^ { \mathrm { comb } } } \\
{ \mathrm { t } \cdot \operatorname { c o n n e c } _ { \mathrm { A } , \mathrm { A } ^ { \prime } , \mathrm { i } } ^ { \mathrm { comb } } } & { \text { if } } & { \Delta \mathrm { H } \geq \mathrm { t } \cdot \operatorname { c o n n e c } _ { \mathrm { A } , \mathrm { A } ^ { \prime } , \mathrm { i } } ^ { \text { comb } } }
\end{array} \quad \left\{\begin{array}{c}
\forall \text { Comb } \\
\forall \mathrm{A}, \mathrm{A}^{\prime} \in \mathrm{Z} \\
\forall \mathrm{A} \neq \mathrm{A}^{\prime} \\
i \in N
\end{array}\right.\right.
\end{aligned}
$$




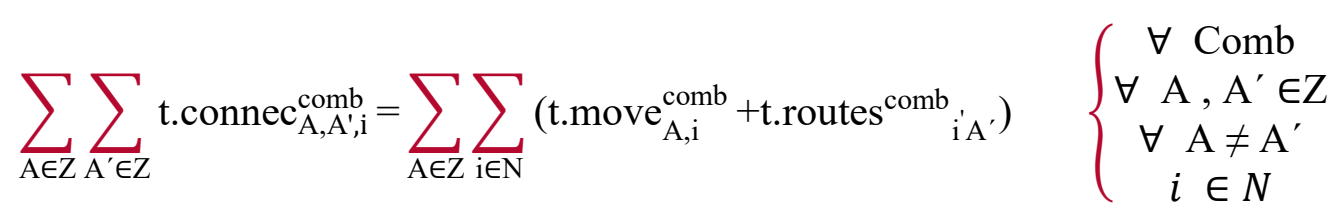

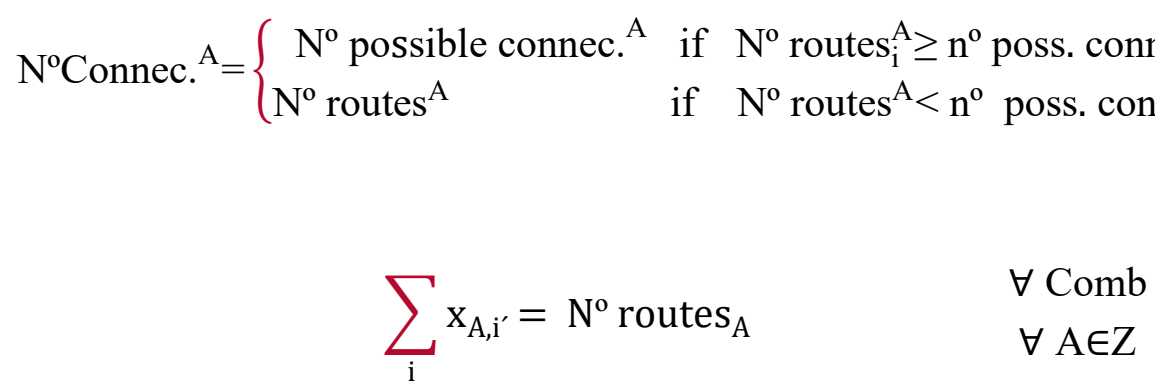

$$
\begin{aligned}
& \begin{array}{ll}
\sum_{\mathrm{A}} \mathrm{x}_{\mathrm{A}, \mathrm{i}^{\prime}}=1 & \forall \mathrm{Comb} \\
& \forall \mathrm{i} \in \mathrm{N}
\end{array}
\end{aligned}
$$

Where:

- $\Delta \mathrm{H}=$ time window necessary to connect the schools.

- $\quad$ T. max. = Maximum time allowed to cover the route.

- $\quad \mathrm{N}^{\mathrm{o}}$ routes ${ }^{\mathrm{A}}=$ Number of trips made to school A or, similarly, the number of buses.

- $\quad \mathrm{N}^{\mathrm{o}}$ connec. ${ }^{\mathrm{A}}=$ the number of connections made from school $A^{\prime}$ to the other schools.

- $\mathrm{N}^{\mathrm{o}}$ poss. connec. ${ }^{\mathrm{A}}=$ is the number of possible connections that can be made from school $A$ to the other schools complying with the time window constraint.

- $\quad \mathrm{x}_{\mathrm{A}, \mathrm{i}}^{\mathrm{comb}}=$ dummy variable which could take a value of 1 if there is enough time to use one of the buses that arrives to A to perform the service of route $\mathrm{i}$.

- t.connec ${ }_{\mathrm{A}, \mathrm{A}^{\prime}, \mathrm{i}}^{\mathrm{comb}}=$ journey time from school A to school $\mathrm{A}^{\prime}$ through the header $\mathrm{i}$, for any combination.

- $\quad$ t.move $\mathrm{A}_{\mathrm{A}, \mathrm{i}}^{\mathrm{comb}}=$ journey time from school $\mathrm{A}$ to header of route $\mathrm{i}$, which is a route to destination school A'.

- t.route $^{\mathrm{comb}}{ }_{\mathrm{iA}}=$ journey time of the route from header $i^{\prime}$ to school $A^{\prime}$.

Equations (8), (9), (10) and (11), represent how the time window is obtained, in other words, where each school is located within the time band $\left(\mathrm{A}, \mathrm{A}^{\prime} \ldots, \mathrm{A}^{\mathrm{n}-1}, \mathrm{~A}^{\mathrm{n}}\right)$, knowing that the time position of schools varies up to make all possible temporary combinations. Therefore, the time window will be the difference between the start time of the last school situated in the time band minus the start time of the first school (ec. 11). 
Constraint (12) represents whether it is possible to make connections between schools and route headers with other schools and constraints (13) and (14) represent their duration. (Fig. $3)$.

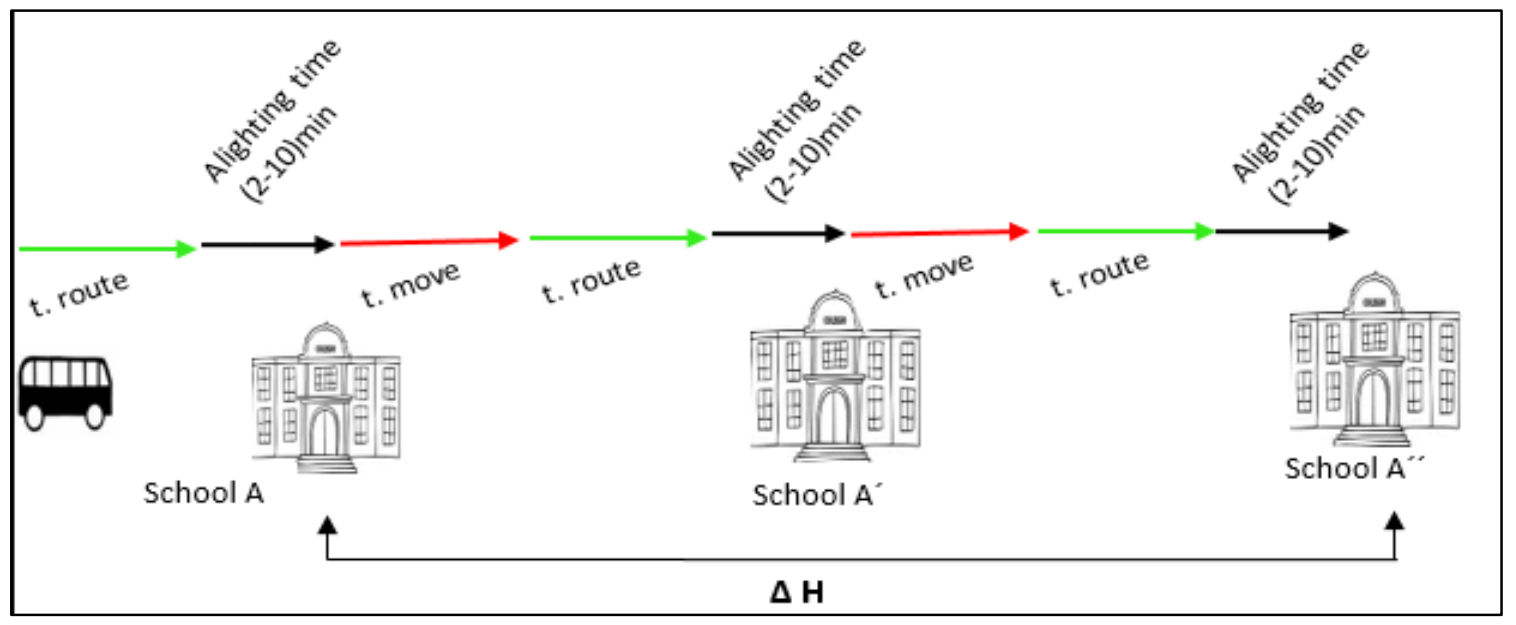

\section{Figure 3. Time band. Connection times between schools}

Constraint (15) represents the requirement of the availability of an adequate number of buses to connect the schools, in other words, the number of connections will be (at the most) the number of routes (buses) which the connecting school has available. Furthermore, constraints (16) and (17) stop the headers being connected by more than one vehicle.

Once the vehicle planning problem has been solved for all the combinations of $\Delta H-n^{o}$ routes - maximum time, multiple alternatives become available which have minimised the number of buses required. From these multiple alternatives (Alt.) we know:

- $\quad \mathrm{N}^{\mathrm{o}}$ of buses required

- Time required to cover each route

- Time window required for that alternative

- Km driven by each bus

However, not all of these alternatives are going to be optimal from an economic or social aspect so a pre-analysis is performed, as a function of the number of buses ( $\mathrm{N}^{\circ}$ buses), time window $(\Delta \mathrm{H})$, average journey times ( $\left.\mathrm{T}_{\text {average}}\right)$ and average maximum time for schools routes ( $\mathrm{T}_{\text {aver.max. }}$ ), to find the solutions of the multiple objective optimisation model. This requires that three of these variables are fixed and the other is minimized, knowing that $\mathrm{T}_{\text {average }}$ and $\mathrm{T}_{\max }$ are connected:

$$
\min \left(\mathrm { No } \text { buses) Alt } \quad \forall \left\{\begin{array}{c}
\Delta \mathrm{H}^{\mathrm{i}}=\Delta \mathrm{H}^{\mathrm{i}+1} \\
\mathrm{~T}_{\text {average }}=\mathrm{T}_{\text {average }}^{\mathrm{i}+1} \\
\mathrm{~T}_{\max } \mathrm{i}=\mathrm{T}_{\max }^{\mathrm{i}+1}
\end{array} \quad\right.\right. \text { Alt }
$$




$$
\begin{aligned}
& \min (\Delta \mathrm{H})^{\text {Alt }} \quad \forall\left\{\begin{array}{c}
\mathrm{N}^{\mathrm{o}} \text { buses }^{\mathrm{i}}=\mathrm{N}^{\text {o }} \text { buses }^{\mathrm{i}+1} \\
\mathrm{~T}_{\text {average }}^{\mathrm{i}}=\mathrm{T}_{\text {average }}^{\mathrm{i}+1} \\
\mathrm{~T}_{\text {max }} \mathrm{i}=\mathrm{T}_{\max }^{\mathrm{i}+1}
\end{array} \quad\right. \text { Alt } \\
& \min \left(\mathrm{T}_{\text {average }}\right)^{\text {Alt }} \quad \forall\left\{\begin{array}{c}
\mathrm{N}^{\mathrm{o}} \text { buses }^{\mathrm{i}}=\mathrm{N}^{\mathrm{o}} \text { buses }^{\mathrm{i}+1} \\
\Delta \mathrm{H}^{\mathrm{i}}=\Delta \mathrm{H}^{\mathrm{i}+1} \\
\mathrm{~T}_{\text {ave.max. }}^{\mathrm{i}}=\mathrm{T}_{\text {ave.max. }}^{\mathrm{i}+1}
\end{array} \quad\right. \text { Alt } \\
& \min \left(\mathrm{T}_{\text {ave.max. }}\right)^{\text {Alt }} \quad \forall\left\{\begin{aligned}
\mathrm{N} \text { o } \text { buse }^{\mathrm{i}}= & \text { No } \text { buses }^{\mathrm{i}+1} \\
\Delta \mathrm{H}^{\mathrm{i}} & =\Delta \mathrm{H}^{\mathrm{i}+1} \\
\mathrm{~T}_{\text {average }} & =\mathrm{T}_{\text {average }} \mathrm{i}+1
\end{aligned} \in\right. \text { Alt }
\end{aligned}
$$

Where:

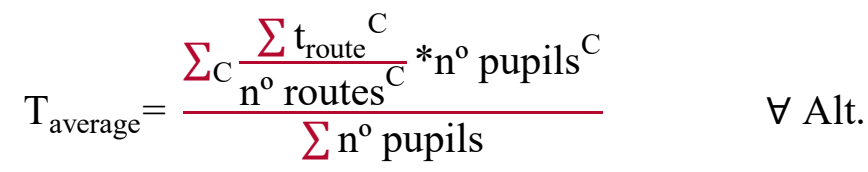

$$
\begin{aligned}
& \mathrm{T}_{\text {ave.max. }}=\frac{\sum_{\mathrm{C}}\left(\mathrm{T}_{\text {ave.max. }}{ }^{*} \mathrm{n}^{\mathrm{o}} \text { pupils }\right)}{\sum \mathrm{n}^{\mathrm{o}} \text { pupils }} \quad \forall \text { Alt. }
\end{aligned}
$$

With this pre-analysis, those alternatives that minimize the economic and social cost are obtained.

\subsubsection{Programming the planning bus fleet}

A program written in Python 3.5 has been used to plan the bus fleet. It provides a faster way to efficiently resolve the issue, and the possibility of applying this methodology in any generic case (regardless of the number and size of schools).

The program's input data are the results obtained from the routing problem for each school: $\mathrm{n}^{\mathrm{o}}$ routes, maximum time allowed to cover the route, journey time of the route and header of the route.

Besides an extensive use of the standard library (particularly the concurrent.futures module for easy handling of parallel tasks, and many of itertools' functions), several external modules have been utilised: numpy (Van der Walt, 2011), for easy and fast matrix manipulation; dill (Mckerns, 2011), to back up the program's output as native Python objects that could not be serialised with pickle; easygui, to effortlessly create a working GUI; and the optimization package PuLP's implementation of the COIN-OR algorithm (Lougee-Heimer, 2003) and openpyxl to handle importing and exporting data to and from Excel files. 


\subsubsection{Data handling}

To attain a good performance while performing the program's tasks, how long it takes one bus which starts at a school "A" to travel to another school's ("B") route header and follow it to its end is stored in the following data structure, called "time_data", which is implemented by a matrix, inside a dictionary, inside a list:

time_data[school_B][(number_of_routes, max_time $)][$ school_A, route] = time

To loop efficiently over all relevant arrival times to the different schools, it is convenient to use an OrderedDict object, called "schedule", which will contain lists of schools that start at the same instant:

Schedule $[$ time $]=[$ school_0,... school_n $]$

Once a routing choice (number of buses, and maximum time of the routes) and a bus arrival timetable have been defined, the adjacency matrix between schools and route headers can be built using a numpy array composed of boolean objects.

After the number of buses required to service a planning choice has been found, each case is stored in "solution", a series of nested Python's DefaultDicts:

Solution [number of buses][time between earlier and latest bus arrival][mean time children stay on the bus][weighted maximum time children stay on the bus][each school's routing choice $]=[$ list of all schedules that can be used to reach this case $]$

\subsubsection{Increasing computing performance}

Whenever the complexity of the tasks made it approachable, functional programming was utilised, using mainly Python's map and itertools.starmap functions, as well as numpy's batch processing methods.

When looping over all possible cases, the number of buses needed is the only required information; which buses serve which routes is not useful. Thus, instead of solving the full linear programming problem (4), the script solves a smaller case, which has a solution functionally related to the full problem's one, and can be solved much quicker. This is achieved by manipulating the adjacency matrix in the following way:

a. Each school can initially share as many buses as routes serve it.

b. Remove columns that add up to less than 2: ("sum")

If sum $==0$ : no extra work is needed.

○ If sum $==1$ :

- We increase the number of times a bus is shared between schools ("n_shared") by 1 . 
- We decrease the number of buses available at that row's school by 1 . If it reaches zero, we remove that school's row and go back to b.

After this process, we will either have a zero-dimension matrix, in which case the number of buses needed for the current planning option would be the total number of routes minus "n_shared"; or a non-zero adjacency matrix, which will be sent, along each remaining school's still shareable buses, to PuLP's COIN LP solver. In this instance, the number of buses needed would be the total number of routes, minus "n_shared", minus the solution to the LP problem.

To take full advantage of multi-core processors, parallel programming has been implemented, a process greatly simplified by Python concurrent.futures module. A recursive function is used to cover all meaningfully different solutions, and each main branch is solved asynchronously by a different process. Each result is sent to a queue shared by all of them, from where is taken by another independent task that stores, and analyses the data.

\subsubsection{Data output}

The script can present the information stored in the structure "time_data" in three different ways:

- Raw output, which includes all cases that were analysed.

- Filtered output, described in (18), (19), (20), (21): as the script covers the search space, it keeps track, for each condition, of the minimum value it has found for the objective variable, for every combination of the other three. At the end, all cases that do not present a minimum value for any of the four conditions are discarded.

E.g. if a solution has already been stored, characterized by $\left(\mathrm{N}^{\circ}\right.$ buses, $\Delta \mathrm{H}, \mathrm{T}_{\text {average, }}$, $\left.\mathrm{T}_{\max }\right)$ and a new one is $\left(\mathrm{N}^{\circ}\right.$ buses', $\left.\Delta \mathrm{H}^{\prime}, \mathrm{T}_{\text {average }}, \mathrm{T}_{\max }{ }^{\prime}\right)$, the latter would not be selected by (18) if: $\mathrm{N}^{\circ}$ buses $<\mathrm{N}^{\circ}$ buses' $, \Delta H=\Delta \mathrm{H}^{\prime}, \mathrm{T}_{\text {average }}=\mathrm{T}_{\text {average' }}, \mathrm{T}_{\max }=\mathrm{T}_{\max }{ }^{\prime}$

- Pareto frontier output: the program returns the set of possible choices that are Paretoefficient. These are found as the script processes all relevant scenarios:

a. We initialize a list of candidates "L" with the worst possible solution: float ("inf") for each variable.

b. As each case "c" is solved:

- If any alternative stored in L strictly dominates c (at least one improvement, and no set-backs):

- We discard c.

- else:

- We discard from $\mathrm{L}$ all choices that are strictly dominated by c.

- $\mathrm{c}$ is added to $\mathrm{L}$.

\subsection{Calculating economic cost}


Once the solutions to the multiple objective optimisation model are available, the economic cost of each solution can be calculated. This process was supported by a previous study on school transport costs, Ibeas et al. (2006). The duration of the routes and the required time windows, variables which affect the users, are also known for each solution.

As the proposed model is aimed at supporting future decision makers on questions of school transport a range of solutions are available; the different weights placed on each variable (economic cost, journey time or time window) provide different solutions.

\section{APPLICATION OF THE PROPOSED MODEL}

The proposed model has been applied to an area in the region of Cantabria (Spain) containing three primary schools (CP. Santa Juliana, CP. Manuel Liaño Beristaín and CP. Cantabria). The following information is known about these schools: the number of pupils and the destination schools of those using school transport and the location of the stops and the number of pupils at each one.

The routing problem has been solved considering the number of routes and the constraint on journey time as variables. The ArcGis geographic information system software was used to solve the problem and a total of 21 solutions were found for combinations of the number of routes and maximum time variables, as shown in table 1.

\begin{tabular}{|c|c|c|c|c|}
\hline & $\mathrm{N}^{\mathrm{o}}$ pupils & $\mathrm{N}^{\mathrm{o}}$ routes & Max. time & $\mathrm{N}^{\mathrm{o}}$ solutions \\
\hline CP. Santa Juliana & 85 & $2-3-4$ & \multirow{3}{*}{$30-45-60$} & 8 \\
\hline CP. Manuel Liaño Beristaín & 55 & $1-2$ & & 4 \\
\hline CP. Cantabria & 244 & $5-6-7$ & & 9 \\
\hline
\end{tabular}

Table 1. Combinations for solving the routing problem

The figure 4 represents an example of the solution of a routing problem: the case of Santa Juliana School with four routes (each one in different colour) and maximum time to cover the route is 30 minutes. The journey time of each route is shown as well as the location of the bus stop and the school. 


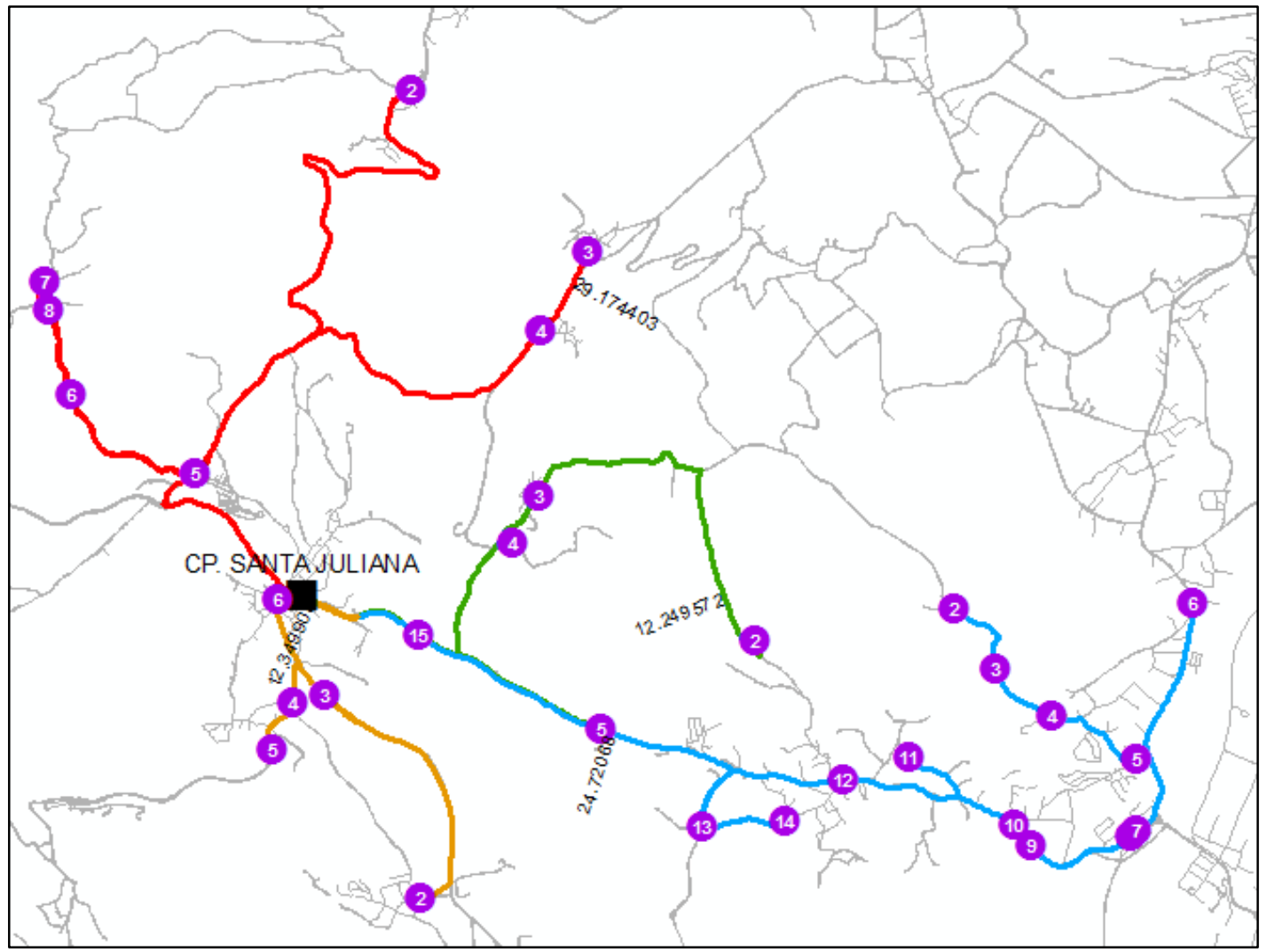

Figure 4. Solution of routing problem: Santa Juliana's school, $n^{0}$ routes $=4$ and t.max=30 minutes.

The second phase solves the planning problem using the solutions provided by the routing problem. The application created in Python for this step has been implemented obtaining 17.021 possible alternatives (ec.5). It is observed how increases the required number of buses when the time window decreases or average travel time increases.

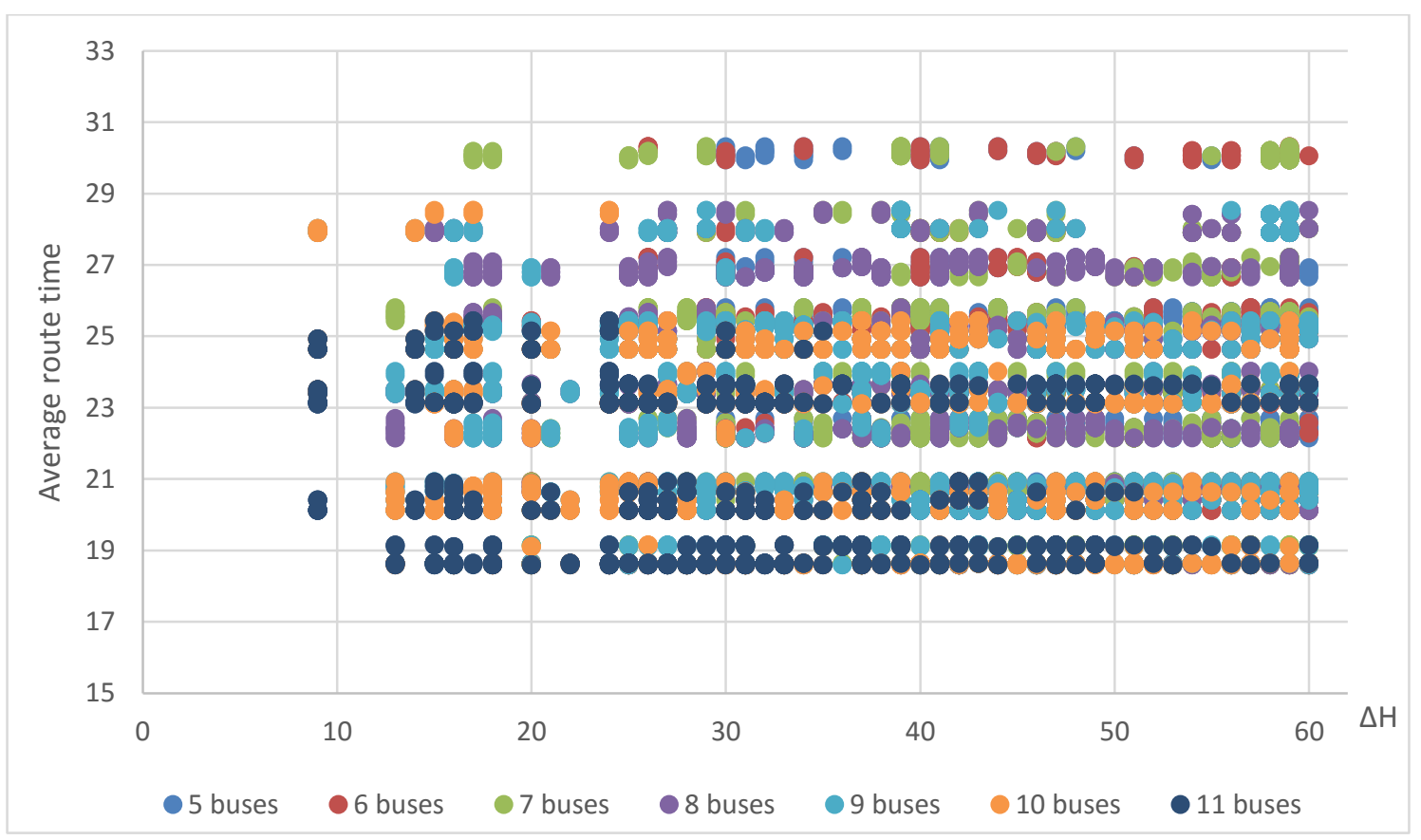

Figure 5. Time window vs Average route time 
However, none of these alternatives are going to be optimal from an economic or social aspect until pre-analysis, as mentioned above, is performed (function of the number of buses, average journey time, maximum time for school routes and time window). The figure 6 represents the 71 results obtained for the multiple objective optimisation model and the current case, which has not changes in start school times. It shows shows that to attain the minimum average route time and time window, 11 buses are needed. However, if 5 buses are used the average route time and the window time significantly increase. In addition, there are also cases without changes in school schedules occur $(\Delta \mathrm{H}=0)$ but their routes vary compared to the current situation because they are historical routes that have not been updated.

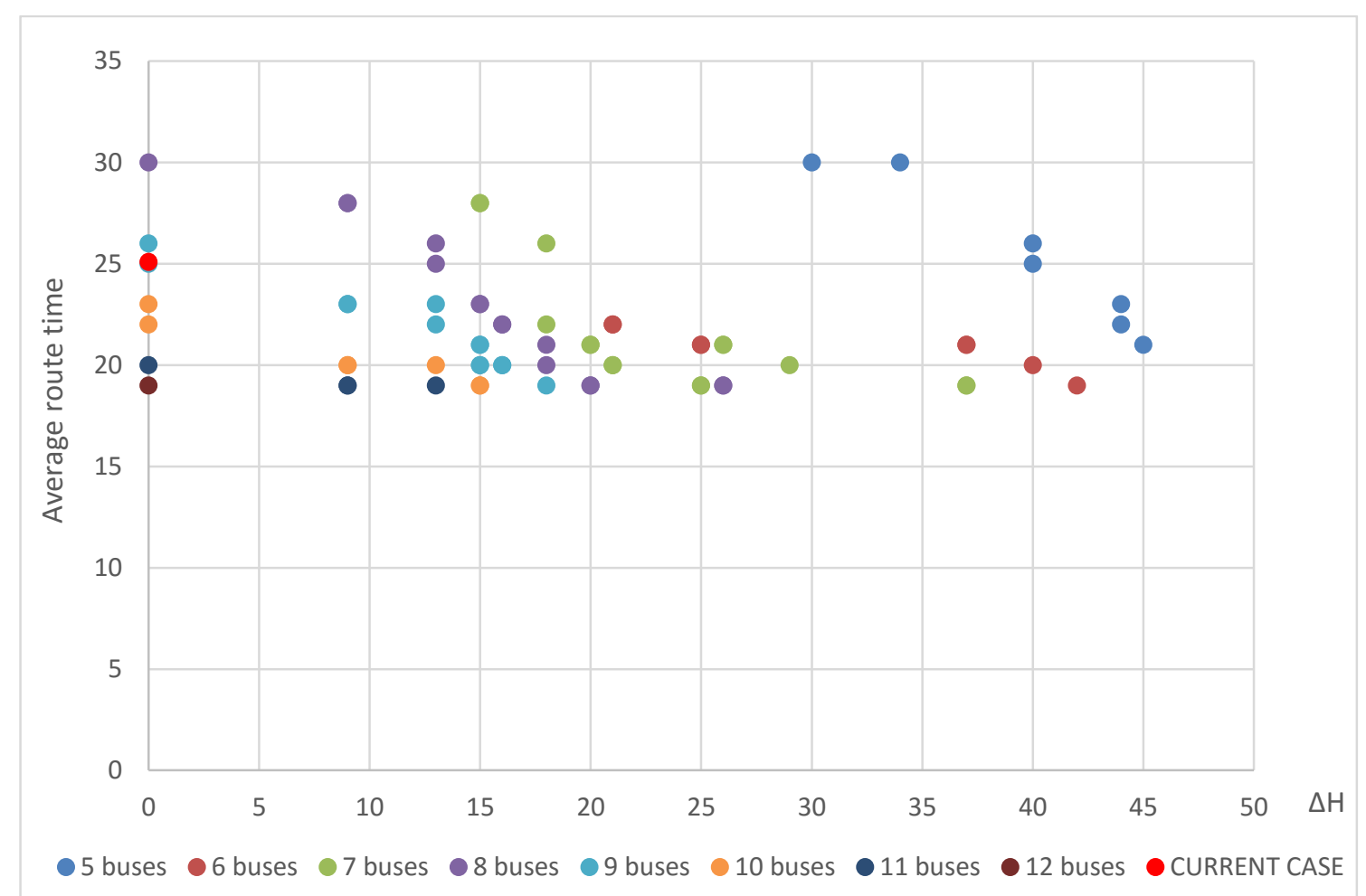

Figure 6. Window time vs average route time vs $n^{\circ}$ of buses.

Once the start time of each schools is known, those having earlier or later opening times are chosen from the cases shown in table 2. The figure 7 shows the cases for those 71 results and the current case, and it is observed that cases $\mathrm{A}$ and $\mathrm{F}$ are the most frequent for smaller number of buses and lower average route time. 


\begin{tabular}{|c|c|c|}
\hline & From & To headers of \\
\hline case A & CP. Cantabria & $\begin{array}{c}\text { CP. Manuel Liaño Beristaín and/or } \\
\text { CP. Santa Juliana }\end{array}$ \\
\hline case B & CP. Santa Juliana & $\begin{array}{c}\text { CP. Cantabria and/or CP. Manuel } \\
\text { Liaño Beristaín }\end{array}$ \\
\hline case $\mathrm{C}$ & CP. Manuel Liaño Beristaín & $\begin{array}{l}\text { CP. Cantabria and/or CP. Santa } \\
\text { Juliana }\end{array}$ \\
\hline case D & $\begin{array}{l}\text { CP. Cantabria and/or CP. Santa } \\
\text { Juliana }\end{array}$ & CP. Manuel Liaño Beristaín \\
\hline case $\mathrm{E}$ & $\begin{array}{c}\text { CP. Cantabria and/or CP. Manuel } \\
\text { Liaño Beristaín }\end{array}$ & CP. Santa Juliana \\
\hline case $\mathrm{F}$ & $\begin{array}{c}\text { CP. Santa Juliana and/or CP. Manuel } \\
\text { Liaño Beristaín }\end{array}$ & CP. Cantabria \\
\hline case $\mathrm{G}$ & \multicolumn{2}{|c|}{ No changes in start school time. } \\
\hline
\end{tabular}

\section{Table 2. Connecting cases between schools}

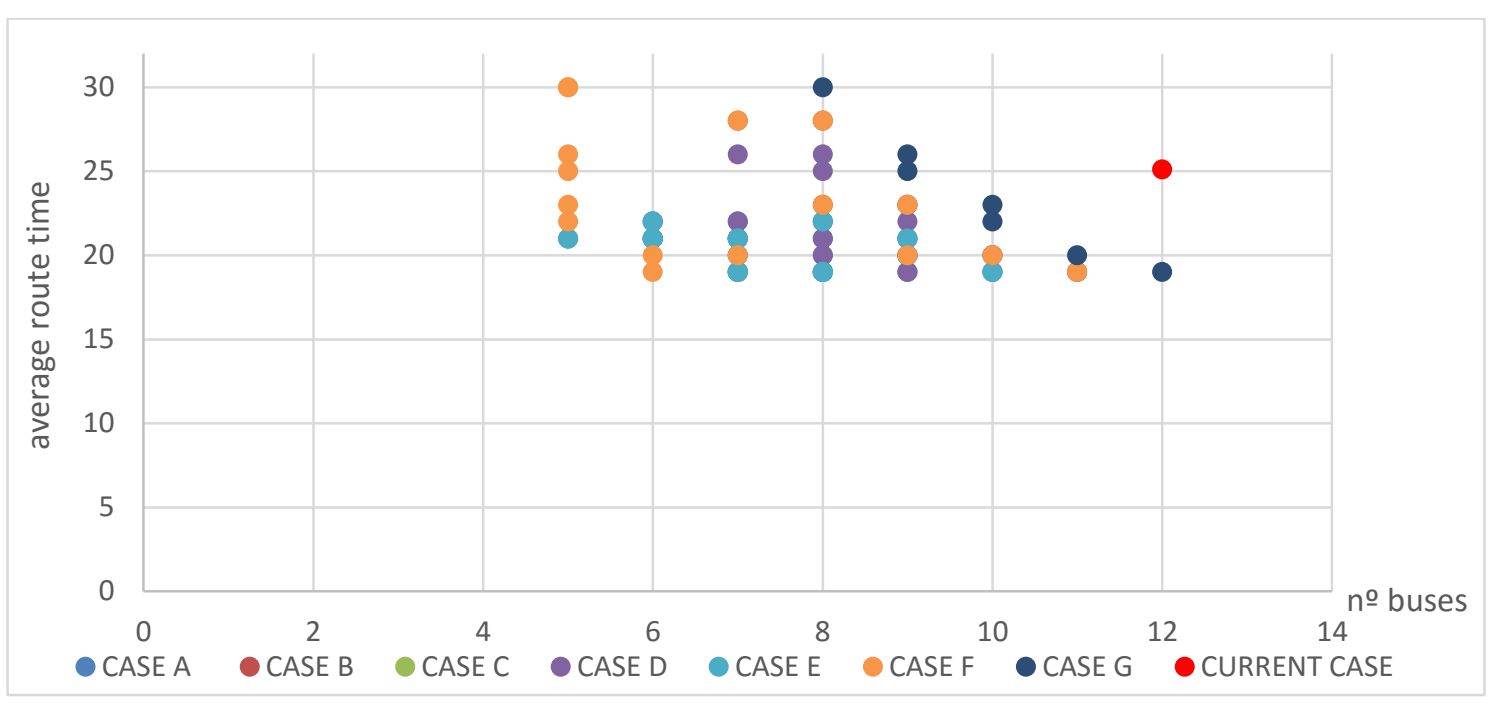

\section{Figure 7. Cases of connectivity vs $\mathbf{N}^{\circ}$ buses vs Average route time}

As this is a support model aimed at future decision makers, they will be the ones who determine which of the alternatives is the definitive solution, depending on the importance they place on the economic and social costs. The figure 8 represents the case F (buses connecting Santa Juliana school and Manuel Liaño Beristaín school to headers of Cantabria school), which involves 13 of the 71 results, each one is represented in a different colour and the red one is the actual situation, unmodified start school time. It shows the results of the objective function: economic cost, time window and average route time. There are fewer buses used by all the solutions than in the current situation (without changes being made to school timetables) and even the average journey time is reduced for some of them. The 
number of buses required by each of the alternatives is directly related to the economic cost which has enabled the authors to calculate the saving as between $16.5 \%$ and $33.7 \%$.

For the other cases similar results were obtained, always improving economic cost (between 2,7-35,1\%) and sometimes social cost also, but for high economic savings the social cost significantly decreases.

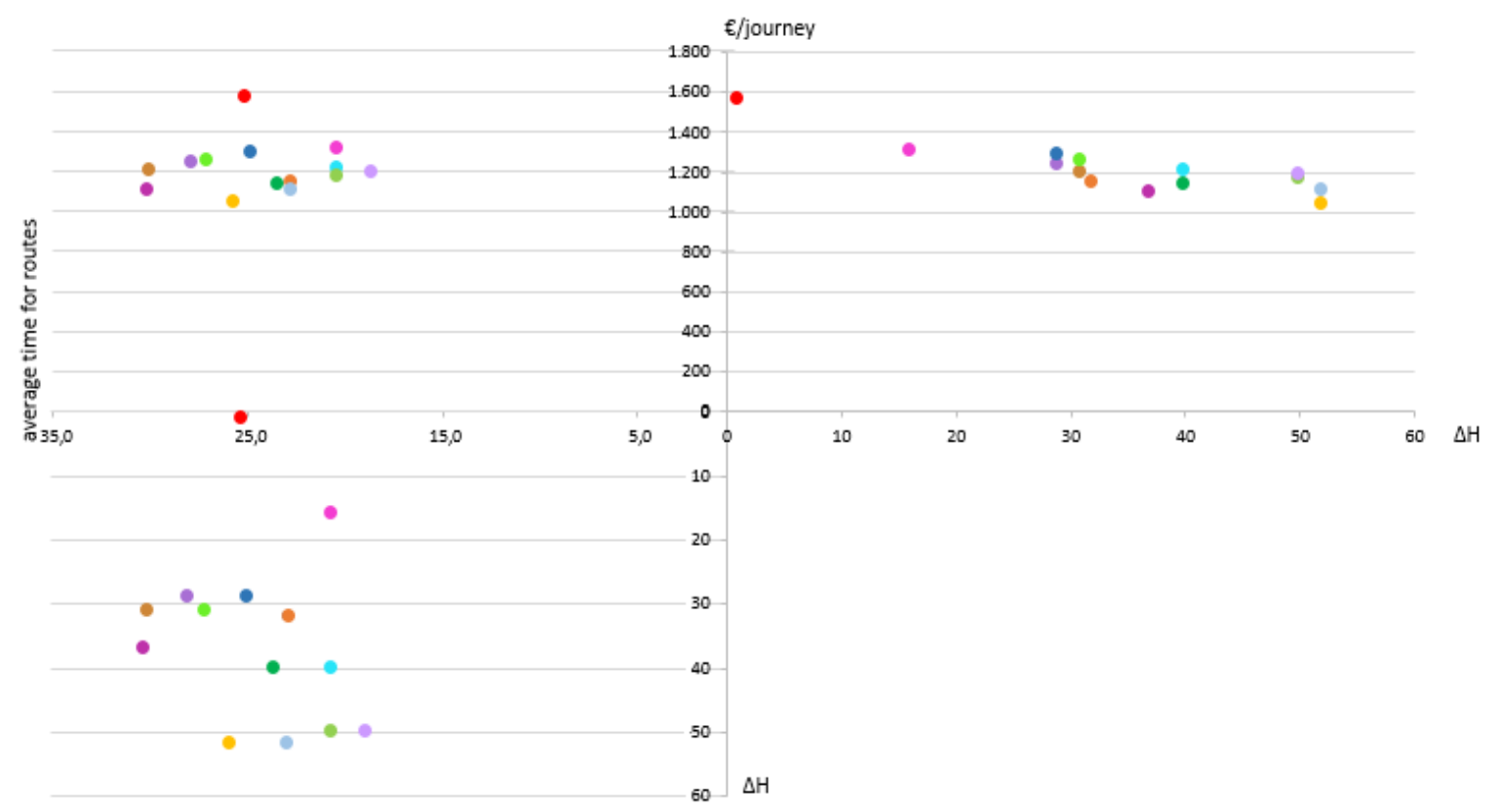

Figure 8. Case F. Result of the objective function: Economic cost vs $\Delta H$ vs average route time

\section{CONCLUSIONS}

The main contribution made by this work is that it allows school opening and closing times to be modified by considering the routing problem of each school together with the general problem of timetables in such a way that planners can plan the routes taken by the school buses and thereby minimise the number of buses being used at the same time as considering journey times. School transport is optimised from both the administration's and users' points of view by considering economic and social aspects which give extra value to the model. A multiple objective optimisation model has been formulated to support future transport decision makers which provide more than one solution as the variables used are not interrelated. In addition, the application created to solve the planning bus fleet, solve this step in less than 2 minutes, and provides the possibility of applying this methodology in any generic case.

The model was applied to an area in Cantabria (Spain) where 3 primary schools are located with a total of 384 pupils using school transport. Seventy-one possible solutions were found, 
all of which reduce the economic costs by between $2,7 \%$ and $35,1 \%$ and in certain cases even managed to reduce journey times of the school buses.

\section{REFERENCES}

BEKTAŞ, T.; ELMASTAŞ, S. (2007) Solving school bus routing problems through integer programming. Journal of the Operational Research Society, 2007, vol. 58, no 12, p. 15991604.

BENNETT, B. T., y GAZIS, D. C. (1972). School bus routing by computer. Transportation Research, 6(4), 317-325.

BODIN, L. D. (1975). A taxonomic structure for vehicle routing and scheduling problems. Computers y Urban Society, 1(1), 11-29.

BODIN, L. D., Y BERMAN, L. (1979). Routing and scheduling of school buses by computer. Transportation Science, 13(2), 113-129.

BRACA, J., BRAMEL, J., POSNER, B., Y SIMCHI-LEVI, D. (1997). A computerized approach to the New York City school bus routing problem. IIE transactions, 29(8), 693702.

CORDEAU, J. F., LAPORTE, G., y MERCIER, A. (2001). A unified tabu search heuristic for vehicle routing problems with time windows. Journal of the Operational research society, 52(8), 928-936.

DAZA, J. M., MONTOYA, J. R., y NARDUCCI, F. (2009). Resolución del problema de enrutamiento de vehículos con limitaciones de capacidad utilizando un procedimiento metaheurístico de dos fases. Revista EIA, 12, 23-38.

DESROSIERS, J., SOUMIS, F., DESROCHERS, M., y SAUVEGERAD, M. (1986). Methods for routing with time windows. European Journal of Operational Research, 23(2), 236-245.

FÜGENSCHUH, A. (2007). Solving a school bus scheduling problem with integer programming. European Journal of Operational Research, 193(3), 867-884.

GARCIA-NAJERA, A., Y BULLINARIA, J. A. (2011). An improved multi-objective evolutionary algorithm for the vehicle routing problem with time windows. Computers $y$ Operations Research, 38(1), 287-300.

GAVISH, B., SCHWEITZER, P., Y SHLIFER, E. (1978). Assigning buses to schedules in a metropolitan area. Computers y Operations Research, 5(2), 129-138. 
GLOVER, F. Y LAGUNA, M. (1997). Tabu Search. Kluver Academic Publishers, Boston.

HO, S. C., Y HAUGLAND, D. (2004). A tabu search heuristic for the vehicle routing problem with time windows and split deliveries. Computers y Operations Research, 31(12), 1947-1964.

IBEAS, A., LUIS MOURA, J., DELL'OLIO, L., y de DIOS ORTÚZAR, J. (2006). Costing school transport in Spain. Transportation planning and technology, 29(6), 483-501.

IBEAS, A., MOURA, J. L., y DELL'OLIO, L. (2009). Planning school transport: design of routes with flexible school opening times. Transportation planning and technology, 32(6), 527-544.

KIM, B. I., KIM, S., y PARK, J. (2012). A school bus scheduling problem. European Journal of Operational Research, 218(2), 577-585.

KONTORAVDIS, G., Y BARD, J. F. (1995). A GRASP for the vehicle routing problem with time windows. ORSA journal on Computing, 7(1), 10-23.

LI, L. Y. O., y FU, Z. (2002). The school bus routing problem: a case study. Journal of the Operational Research Society, 552-558.

LÖBEL, A. (1998). Vehicle scheduling in public transit and Lagrangean pricing. Management Science, 44(12-part-1), 1637-1649.

LOUGEE-HEIMER, R. (2003). The Common Optimization INterface for Operations Research: Promoting open-source software in the operations research community. IBM Journal of Research and Development, 47(1), 57-66.

MCKERNS, M. M., STRAND, L., SULLIVAN, T., FANG, A., \& AIVAZIS, M. A. (2012). Building a framework for predictive science. arXiv preprint arXiv:1202.1056.

NEWTON, R. M., Y THOMAS, W. H. (1974). Bus routing in a multi-school system. Computers y Operations Research, 1(2), 213-222.

ORLOFF, C. S. (1976). Route constrained fleet scheduling. Transportation Science, 10(2), 149-168.

PARK, J., Y KIM, B. I. (2010). The school bus routing problem: A review. European Journal of operational research, 202(2), 311-319.

PARK, J., TAE, H., Y KIM, B. I. (2012). A post-improvement procedure for the mixed load school bus routing problem. European Journal of Operational Research, 217(1), 204-213. 
PEPIN, A. S., DESAULNIERS, G., HERTZ, A., Y HUISMAN, D. (2009). A comparison of five heuristics for the multiple depot vehicle scheduling problem. Journal of Scheduling, 12(1), 17-30.

SALHI, S., Y SARI, M. (1997). A multi-level composite heuristic for the multi-depot vehicle fleet mix problem. European Journal of Operational Research, 103(1), 95-112.

SANHUEZA, N. D. A., NÍÑEZ, C. E. O., Y BELMAR, G. E. P. (2012). Un modelo de programación lineal entera mixta para el problema de ruteo de vehículos en el transporte escolar.

SCHITTEKAT, P., KINABLE, J., SÖRENSEN, K., SEVAUX, M., SPIEKSMA, F., y SPRINGAEL, J. (2013). A metaheuristic for the school bus routing problem with bus stop selection. European Journal of Operational Research, 229(2), 518-528.

SPADA, M., BIERLAIRE, M., Y LIEBLING, T. M. (2005). Decision-aiding methodology for the school bus routing and scheduling problem. Transportation Science, 39(4), 477-490.

SWERSEY, A. J., Y BALLARD, W. (1984). Scheduling school buses. Management Science, 30(7), 844-853.

THANGIAH, S. R., FERGANY, A., WILSON, B., PITLUGA, A., Y MENNELl, W. (2008). School bus routing in rural school districts. In Computer-aided Systems in Public Transport (pp. 209-232). Springer Berlin Heidelberg.

VAN DER WALT, S., COLBERT, S. C., \& VAROQUAUX, G. (2011). The NumPy array: a structure for efficient numerical computation. Computing in Science \& Engineering, 13(2), 22-30.

YU, T., Y DAVIS, L. (2008). An Introduction to Evolutionary Computation in Practice. Evolutionary Computation in Practice, 88, 1-8.

ZUÑIGA, E. A., y GURROLA, L. C. G. Un algoritmo GRASP para un problema de rutas de vehículos escolares aplicado al transporte de personal de una empresa de manufactura. 